\title{
MET-targeted therapy for gastric cancer: the importance of a biomarker-based strategy
}

\author{
Hisato Kawakami ${ }^{1} \cdot$ Isamu Okamoto $^{2}$
}

Received: 29 September 2015/ Accepted: 29 November 2015/Published online: 21 December 2015

(c) The International Gastric Cancer Association and The Japanese Gastric Cancer Association 2015

\begin{abstract}
The MET protooncogene encodes the receptor tyrosine kinase c-MET (MET). Aberrant activation of MET signaling occurs in a subset of advanced malignancies, including gastric cancer, and promotes tumor cell growth, survival, migration, and invasion as well as tumor angiogenesis, suggesting its potential importance as a therapeutic target. MET can be activated by two distinct pathways that are dependent on or independent of its ligand, hepatocyte growth factor (HGF), with the latter pathway having been attributed mostly to MET amplification in gastric cancer. Preclinical evidence has suggested that interruption of the HGF-MET axis either with antibodies to HGF or with MET tyrosine kinase inhibitors (TKIs) has antitumor effects in gastric cancer cells. Overexpression of MET occurs frequently in gastric cancer and has been proposed as a potential predictive biomarker for anti-MET therapy. However, several factors can trigger such MET upregulation in a manner independent of HGF, suggesting that gastric tumors with MET overexpression are not necessarily MET driven. On the other hand, gastric cancer cells with MET amplification are dependent on MET signaling for their survival and are thus vulnerable to MET TKI treatment. Given the low prevalence of MET amplification in gastric cancer (approximately $8 \%$ ), testing for this genetic change would substantially narrow the target
\end{abstract}

Isamu Okamoto

okamotoi@kokyu.med.kyushu-u.ac.jp

1 Department of Medical Oncology, Kinki University Faculty of Medicine, 377-2 Ohno-higashi, Osaka-Sayama, Osaka 589-8511, Japan

2 Research Institute for Diseases of the Chest, Graduate School of Medical Sciences, Kyushu University, 3-1-1 Maidashi, Higashiku, Fukuoka 812-8582, Japan population but it might constitute a better biomarker than MET overexpression for MET TKI therapy. We compare aberrant MET signaling dependent on the HGF-MET axis or on MET amplification as well as address clinical issues and challenges associated with the identification of appropriate biomarkers for MET-driven tumors.

Keywords Gastric cancer - MET - Amplification · Hepatocyte growth factor

\section{Introduction}

Gastric cancer is the fourth commonest malignant disease and the second leading cause of cancer death worldwide [1]. Individuals in whom gastric cancer has been newly diagnosed often present with advanced incurable disease. Furthermore, although the most effective treatment for localized disease is surgery, about half of all patients with advanced-stage disease experience recurrence after curative resection. The prognosis for patients with unresectable advanced or recurrent gastric cancer remains poor, with a median survival time of 9-12 months with conventional therapy [2-8].

Certain genetically defined cancers are dependent on a single overactive oncogene for their proliferation and survival, a phenomenon known as "oncogene addiction" that is exemplified by mutant forms of the epidermal growth factor receptor (EGFR) gene and by the EML4-ALK fusion gene in non-small-cell lung cancer (NSCLC) as well as by amplification of the human EGFR2 (HER2) gene in breast cancer. A new generation of drugs-including tyrosine kinase inhibitors (TKIs) and monoclonal antibodies-that selectively target the products of such "driver oncogenes" have shown a therapeutic efficacy greater than that of 
conventional chemotherapy in individuals with these specific molecular alterations [9-12]. In the case of metastatic gastric cancer, trastuzumab, an HER2-targeted antibody, in combination with chemotherapy was found to confer a significant increase in overall survival (OS) compared with chemotherapy alone [median of 13.8 months vs 11.1 months, hazard ratio (HR) of 0.74 with a $95 \%$ confidence interval (CI) of $0.60-0.91$, $P=0.0048$ ] in HER2-positive patients [7], who account for $7-17 \%$ of individuals with this condition [13-15]. Trastuzumab is thus now a standard first-line treatment option for HER2-positive metastatic gastric cancer, and clinical trials evaluating a new class of HER2-targeted drugs such as pertuzumab and T-DM1 in the second-line setting are currently under way. However, for most individuals with metastatic gastric cancer who are negative for HER2, conventional therapy such as doublet or triplet combination chemotherapy remains the only treatment option [16-18]. Further research is thus warranted to identify new therapeutic targets for such patients.

Gastric cancer has been thought to be molecularly heterogeneous, suggesting the existence of driver oncogenes in addition to HER2 that might be amenable to pharmacological inhibition [19, 20]. Emerging evidence suggests that the aberrant activation of MET provides one of the most promising therapeutic targets in gastric cancer, with such activation currently being the subject of intense clinical investigation.

\section{Oncogenic MET activation in cancer}

The mesenchymal-epithelial transition factor protooncogene (MET) encodes the receptor tyrosine kinase c-MET (or MET), for which hepatocyte growth factor (HGF) is the only known ligand. In the canonical HGF-MET signaling pathway, the binding of HGF to MET results in receptor homodimerization, autophosphorylation of tyrosine residues in its carboxyl-terminal domain, and activation of mitogenactivated protein kinase, phosphoinositide 3-kinase, and Rac1-Cdc42 signaling [21]. Whereas normal activation of MET is essential for wound healing and embryonic development [22], aberrant activation of MET signaling in a subset of advanced cancers [23-27] suppresses apoptosis and promotes cell proliferation, motility, migration, and invasion [28]. Furthermore, excessive activation of MET results in the transphosphorylation of and formation of heterodimers with other receptor tyrosine kinases, including EGFR, HER2, HER3, and RET [29]. Such heterodimers allow bypass signaling that can give rise to resistance to EGFR- or HER2targeted therapy, as has been demonstrated in NSCLC cells $[30,31]$ and colorectal cancer cells $[32,33]$ as well as in gastric cancer cells [34-36].
Two types of oncogenic MET signaling have been identified that differ with regard to ligand dependency: HGF-dependent MET activation (HGF-MET axis) and HGF-independent activation of MET, in which genetic alterations give rise to constitutive activation of the kinase [37]. In gastric cancer, gain-of-function mutations of $M E T$ are exceedingly rare [38-40], with ligand-independent activation of MET having been attributed to gene amplification [41-43].

\section{Role of the HGF-MET axis in gastric cancer cells}

Preclinical models have shown that activation of MET signaling by HGF in gastric cancer cell lines promotes tumorigenesis and metastasis. HGF-mediated MET activation has also been found to promote the epithelialmesenchymal transition and to inhibit detachment-induced apoptosis (anoikis) in preclinical models of gastric cancer [44], suggesting that the HGF-MET axis might contribute to metastatic transformation in this malignant disease. Inhibition of HGF-MET signaling with antibodies to HGF or with MET kinase inhibitors attenuates tumor growth and metastatic dissemination in vitro or in vivo [44-46]. Biomarkers able to identify gastric cancer cells that require HGF-mediated activation of MET for their survival have remained obscure, however.

\section{Role of MET amplification in gastric cancer}

A role for $M E T$ amplification in gastric cancer was demonstrated in preclinical studies performed in vitro. Inhibition of MET kinase activity with a MET TKI or MET knockdown by RNA interference resulted in downregulation of AKT and obscure extracellular-signal-regulated kinase phosphorylation and consequent induction of apoptosis in gastric cancer cells positive for MET amplification but not in those negative for this genetic alteration [47-49]. A MET TKI also showed a marked antitumor effect on gastric cancer xenografts positive for MET amplification, whereas it had little effect on those without this genetic change [48]. These results suggested that MET signaling is essential for the survival of gastric cancer cells with MET amplification but not for that of those without it, and they demonstrate that attenuation of MET signaling with a small-molecule MET inhibitor has marked antitumor effects both in vitro and in vivo.

\section{Biomarkers for MET-driven gastric cancer}

Given the efficacy of MET-targeted therapy in preclinical models, it became important to determine the prevalence of MET-driven tumors in patients with metastatic gastric 
cancer. To date, various studies have measured different biomarkers in order to detect aberrant MET activation, including MET protein, MET messenger RNA, and MET gene alterations such as copy number gain and amplification.

\section{MET-targeted therapy for advanced gastric cancer}

Several drugs that target MET signaling, including both antibodies and small-molecule inhibitors, have been evaluated in patients with gastric cancer. Whereas antibodies have been directed against either HGF or MET to prevent ligand-receptor interaction and thereby to block downstream MET signaling, most MET TKIs are designed to target the active site in the intracellular domain of the receptor and thereby to block receptor phosphorylation and downstream signaling. MET TKIs are thus able to inhibit both ligand-dependent and ligand-independent MET activation, whereas antibodies to HGF or MET inhibit only HGF-mediated MET activation.

\section{Targeting of the HGF-MET axis by monoclonal antibodies}

One approach to pathway-selective anticancer therapy is antagonism of ligand-receptor interaction. The evidence implicating aberrant HGF-MET signaling in gastric tumorigenesis together with promising early clinical results obtained with agents that target such signaling has triggered substantial clinical development efforts. The monoclonal antibodies rilotumumab and onartuzumab have been evaluated in phase III trials in gastric cancer.

Rilotumumab (AMG 102) is a fully human monoclonal antibody (IgG2) that binds with high affinity to and neutralizes human HGF [50]. A phase II study evaluating the addition of rilotumumab to the combination of epirubicin plus cisplatin plus capecitabine in patients with gastric or esophagogastric junction adenocarcinoma revealed that those with MET-high tumors (more than $50 \%$ of cells positive for MET expression by immunohistochemistry) had superior survival when treated with rilotumumab compared with those with MET-low tumors (OS of 11.1 months vs 5.7 months, HR of $0.29, P=0.012$ ) [51]. Conversely, patients with MET-low tumors treated with chemotherapy plus rilotumumab tended to have a worse survival compared with those treated with chemotherapy alone [51]. An exposure-response analysis showed that increased exposure to rilotumumab was associated with improvements in both progression-free survival (PFS) and OS in MET-high patients [52].

RILOMET-1, a randomized, global, double-blind, placebo-controlled phase III study of rilotumumab in combination with epirubicin plus cisplatin plus capecitabine as first-line treatment for advanced MET-positive gastric or esophagogastric cancer (NCT01697072), was conducted with OS as the primary end point [53]. Associations between outcome and tumor or circulating biomarkers were also examined as an exploratory analysis. Patient enrollment began in November 2012, but it was announced in November 2014 that the trial had been terminated because a planned safety review found an increase in the number of deaths in the rilotumumab-pluschemotherapy treatment arm (rilotumumab arm, 128 deaths) compared with the chemotherapy-only arm (placebo arm, 107 deaths). As a result, OS (5.7 months vs 5.7 months, HR of 1.37 with a $95 \%$ CI of 1.06-1.78), PFS (9.6 months vs 11.5 months, HR of 1.30 with a $95 \%$ CI of $1.05-1.62)$, and overall response rate (30\% vs $39.2 \%$, odds ratio of 0.67 with a $95 \% \mathrm{CI}$ of $0.46-0.96$ ) were statistically worse in the rilotumumab arm. Furthermore, no subgroups appeared to benefit from rilotumumab treatment, including those patients with a higher percentage of cells with 1+ or greater MET expression [54]. All clinical trials evaluating rilotumumab in gastric cancer were therefore terminated (http://wwwext.amgen.com/media/ media_pr_detail.jsp?year=2014\&releaseID=1992492; accessed 24 September 2015).

Onartuzumab is a fully humanized, monovalent antibody to MET (IgG1) that inhibits HGF binding and subsequent receptor activation [55]. It does not trigger the dimerization and consequent activation of the receptor observed with some bivalent antibodies [56]. In a phase I trial in which onartuzumab showed activity against a variety of tumor types, a complete and durable response was apparent in a female gastric cancer patient with high MET polysomy and MET overexpression [57]. Clinical development of onartuzumab was pursued in NSCLC before gastric cancer. A randomized phase II trial with relapsed NSCLC patients revealed that onartuzumab together with the EGFR TKI erlotinib conferred a better PFS and OS compared with erlotinib alone in MET-positive cases, which were defined prospectively as those in which more than $50 \%$ of tumor cells were positive for MET expression by immunohistochemistry [58]. In contrast, a detrimental effect of the combination therapy compared with erlotinib alone was observed in MET-negative patients. On the basis of these observations, the design of a phase III study (MetLung, NCT1234567) was restricted to MET-positive patients [59]. However, the MetLung study failed to meet its primary end point of OS [60].

For further clinical evaluation of onartuzumab in HER2negative metastatic gastric cancer, a couple of randomized trials were conducted concurrently. YO28252 (NCT01590719) was a phase II trial of onartuzumab plus 
mFOLFOX6 (onartuzumab arm) versus placebo plus mFOLFOX6 (placebo arm) in the first-line setting (planned $n=120$ ), with PFS as the primary end point. This phase II study also planned to evaluate the clinical profile of onartuzumab in MET-positive versus MET-negative patients. However, YO28252 failed to demonstrate efficacy from addition of onartuzumab to mFOLFOX6 therapy (median PFS of 6.77 months for the onartuzumab arm and 6.97 months for the placebo arm; HR of 1.08 with a $95 \%$ CI of 0.71-1.63) [61]. Onartuzumab was also ineffective in the MET-positive subgroup (median PFS of 5.95 months for the onartuzumab arm and 6.8 months for the placebo arm; HR of 1.38 with a $95 \%$ CI of $0.60-3.20$ ). No difference in efficacy was noted with an alternative definition of MET positivity based on staining intensity instead of the percentage of tumor cells positive for MET staining by immunohistochemistry.

MetGastric (YO28322, NCT01662869) was a phase III trial of onartuzumab plus mFOLFOX6 versus placebo plus mFOLFOX6 in the first-line setting (planned $n=800$ ) [62]. Unlike YO28252, MetGastric was restricted to patients with gastric cancer positive for MET by immunohistochemistry. The primary end point of the study was OS in all patients as well as in a subgroup with staining scores of 2 or 3 (on a scale of 0-3) for MET immunohistochemistry (based on previous results for NSCLC [58]). As a consequence of the negative results from YO28252, however, enrollment for MetGastric was stopped early. At data cutoff (April 25, 2014), the intention-to-treat population comprised 562 patients, $26 \%$ of whom in each arm had an OS event. Consistent with the results of the previous phase II study, MetGastric failed to show a benefit for the addition of onartuzumab to mFOLFOX6 therapy both in the intention-to-treat population (median OS of 11.0 months for the onartuzumab arm vs 11.3 months for the placebo arm; HR of $1.38, P=0.244$ ) and in those patients with a MET staining score of 2 or 3 (median OS of 11.0 months for the onartuzumab arm vs 9.7 months for the placebo arm; HR of $0.64, P=0.062$ ) [63].

\section{Issues in the development of HGF- or MET-targeted antibody therapy for advanced gastric cancer}

There are several possible explanations for the disappointing results obtained with rilotumumab and onartuzumab in gastric cancer. In addition to the toxicity of these drugs, one possibility is a failure to identify the appropriate target population, a key and problematic issue in the clinical development of targeted agents.

Overexpression of MET as determined by immunohistochemistry has been extensively examined in gastric tumor tissue. In recent retrospective studies in which the expression of MET was determined by this approach in gastric tumor specimens obtained after tumor resection, MET overexpression was detected in 4-63\% of cases [6469]. Possible reasons for this wide variation in the frequency of this biomarker include the absence of consensus on scoring criteria for MET immunohistochemistry, encompassing the use of different sample types, interreader variability, and differences in tissue processing and storage, primary and secondary antibodies, staining protocols, and scoring methods [70, 71]. Furthermore, increased MET expression in the absence of gene amplification can occur in a manner independent of HGF [72, 73] and as a result of transcriptional upregulation by the products of other oncogenes [74, 75], environmental conditions such as hypoxia [76], and agents secreted by reactive stroma such as inflammatory cytokines and proangiogenic factors [77]. Importantly, it is not always the case that tumors with MET overexpression are MET driven.

The successful development of HER2-directed therapy for gastric cancer has emphasized the importance of rigorous target assessment. Unlike HER2, for which no specific ligand has been identified, MET signaling is activated by $\mathrm{HGF}$ as well as by gene amplification. Most tumors dependent on HER2 signaling can be identified by immunohistochemistry alone, given the agreement in results obtained by this technique and by detection of gene amplification, whereas the relation between MET overexpression and the dependence of a tumor on signaling by the HGF-MET axis remains unclear. The clinical trials of antibodies to HGF or to MET have nevertheless adopted MET overexpression as a biomarker for patient selection, possibly contributing to a failure to identify the appropriate target population. Although previous biomarker studies have found a positive correlation between MET positivity and the efficacy of such antibodies [52, 58], immunohistochemistry alone might not be sufficiently accurate for consistent measurement of MET, as suggested by the retrospective studies mentioned above, indicating that complementary assays are needed. Indeed, although the prevalence of $M E T$ amplification in gastric cancer is on the order of $8 \%$, tumors with MET amplification may overexpress MET but are likely resistant to HGF- or METtargeted antibodies, given that such antibodies inhibit only HGF binding to MET.

In the RILOMET-1 trial, OS, PFS, and response rate were significantly worse in the rilotumumab arm than in the placebo arm among the MET-positive cohort [54]. The reason for this detrimental effect remains unclear, but a possible explanation can be envisioned. HGF-MET signaling was recently shown to be required for the recruitment of antitumoral neutrophils in mice [78]. Deletion of the MET gene in neutrophils was found to be associated with increased tumor growth and metastasis, whereas MET-expressing neutrophils were shown to be enriched 
within tumors and to contribute to cancer cell killing. Such transmigration of antitumoral MET-positive neutrophils was dependent on HGF stimulation. These findings thus raise the possibility that blockade of HGF-MET signaling may promote tumor progression by interfering with the activity of antitumoral neutrophils. Further biomarker studies are thus warranted to identify a gastric cancer subpopulation with a realistic chance of benefiting from therapeutic antibodies to HGF or MET.

\section{Targeting MET amplification with MET TKIs}

In contrast to the development of antibodies specific for HGF or MET, MET TKIs have been examined only in early-phase studies, with no randomized trials of these drugs currently under way in patients with metastatic gastric cancer.

Foretinib (GSK1363089), a multikinase inhibitor targeting MET, RON, AXL, TIE2, and vascular endothelial growth factor receptor 2 , failed to show antitumor activity in a single-arm phase II study of patients with molecularly unselected metastatic gastric cancer or those with $M E T$ amplification-positive tumors [79]. This study enrolled 74 patients, of whom only three individuals manifested $M E T$ amplification as determined by fluorescence in situ hybridization (FISH) and defined as a MET to centromeric portion of chromosome 7 (CEP7) ratio greater than 2 . Twenty patients (27\%) had an increased MET copy number due to polysomy. No patient, including those patients with MET amplification, achieved a complete or partial response.

Tivantinib (ARQ197), a MET TKI with microtubuledisrupting activity similar to that of vincristine [80], also failed to show clinical activity as monotherapy in unselected patients with previously treated metastatic gastric cancer [81]. In this study, no tumor responses were observed among 31 advanced gastric cancer patients, including two individuals with $M E T$ amplification.

Crizotinib (PF-02341066), a TKI that inhibits the tyrosine kinase activity of MET $[48,82]$ as well as that of oncogenic fusion variants of ALK [83], was found to induce a marked clinical response in two of four patients with gastric cancer positive for MET amplification (MET/ CEP7 ratio greater than 2.2) [84]. One patient experienced a rapid symptomatic response, with an increase in appetite, reduction in pain, and improvement in performance status after 1 week of crizotinib treatment. A partial tumor response was revealed by a computed tomography scan at the end of the second treatment cycle ( 8 weeks) and was confirmed at 12 weeks. In the second patient, rapid clinical improvement, with reduced pain and improved performance status after 1 week of crizotinib treatment, was also apparent. The time to progression for these two patients receiving crizotinib treatment was approximately 112 and
105 days, respectively. A recent study also demonstrated the efficacy of crizotinib in a patient with stage IV gastric cancer positive for $M E T$ amplification (MET/CEP7 ratio of 2.0 or greater or 15 or more copies of genes in $10 \%$ or more of tumor cells) [85]. Although crizotinib was administered as a fourth-line therapy in this patient, radiographic evidence of tumor shrinkage and symptomatic improvement were apparent after 3 weeks of treatment.

The clinical activity, safety, and tolerability of AMG 337, a highly selective MET TKI, were also recently investigated in a phase I study including 51 patients with gastroesophageal cancer. Thirteen individuals had tumors positive for $M E T$ amplification as detected by FISH, among whom one patient achieved a complete response that was maintained for 100 weeks and seven patients showed a partial response with a duration of up to 52 weeks, yielding a response rate of $62 \%$ [86].

\section{Future challenges in MET TKI therapy for advanced gastric cancer}

The conflicting clinical results obtained with MET TKIs suggest that there are at least two lessons to be learned before moving forward with MET-targeted therapy. First, it might be better to pursue highly selective MET TKIs rather than multitargeted kinase inhibitors. Otherwise, the relation between drug efficacy and MET amplification is not clear. Second, MET TKIs should be evaluated in a selected population of patients with tumors positive for MET amplification as determined by FISH.

To date, MET amplification has not been consistently well defined, leading to potential confusion between $M E T$ amplification and MET copy number gain [87]. The prevalence of MET amplification has thus varied in the literature. Studies based on FISH analysis have identified MET amplification in up to approximately $8 \%$ of patients with gastric cancer [42, 49, 67, 84, 88, 89], whereas an increase in MET copy number has been found in up to approximately $20 \%$ of gastric cancer patients by Southern blot analysis [41, 43] or by polymerase chain reaction (PCR)-based assays [90-92] (Table 1). As discussed elsewhere [87], whereas Southern blot analysis and PCR-based assays measure a gain in gene copy number regardless of the underlying mechanism, FISH is able to distinguish gene amplification from polysomy. Gastric cancer with an increased MET copy number due to polysomy 7 may not be MET driven, given that breast tumors with an increased HER 2 copy number as a result of polysomy 17 behave as HER2-negative tumors [93]. The finding that approximately $30 \%$ of gastric tumors with an increased $M E T$ copy number manifested polysomy 7 [88] highlights the importance of identification of MET amplification with the use of the definitive assay, FISH. 
Table 1 Prevalence of $M E T$ amplification or increased $M E T$ gene copy number in gastric cancer

\begin{tabular}{|c|c|c|c|c|c|}
\hline Study & Number of patients & Clinical stage & Technique & Classification & Positivity (\%) \\
\hline Janjigian et al. [88] & 38 & $0-\mathrm{IV}$ & FISH & $M E T / C E P 7$ ratio $>2.0$ & 0 \\
\hline Kawakami et al. [49] & 266 & I-IV & FISH & $M E T / C E P 7$ ratio $>2.2$ & 1.5 \\
\hline Lennerz et al. [84] & $\begin{array}{l}267 \text { (junctional and } \\
\text { gastric) }\end{array}$ & 0-IV & FISH & $M E T / C E P 7$ ratio $>2.2$ & 2.2 \\
\hline Hara et al. [42] & 154 & Not specified & FISH & Not specified & 3.9 \\
\hline Yang et al. [85] & 98 & I-III & FISH & $\begin{array}{l}M E T / C E P 7 \text { ratio } \geq 2.0 \text { or } \mathrm{GCN} \geq 15 \text { per } \\
\text { cell in } \geq 10 \% \text { of analyzed cells }\end{array}$ & 4.1 \\
\hline Liu et al. [67] & 196 & I-IV & FISH & $M E T / C E P 7$ ratio $>2.0$ & 6.1 \\
\hline An et al. [89] & 230 & IV or recurrent & FISH & $\begin{array}{l}M E T / C E P 7 \text { ratio }>2.0 \text { or } \mathrm{GCN} \geq 15 \text { per } \\
\text { cell in } \geq 10 \% \text { of analyzed cells }\end{array}$ & 8.3 \\
\hline Graziano et al. [90] & 216 & IIA-IIIC & PCR based & $\mathrm{GCN} \geq 5$ & 9.7 \\
\hline Tsugawa et al. [43] & 70 & I-IV & Southern blot analysis & Ratio $>2$ (relative to normal mucosa) & 10.0 \\
\hline Nakajima et al. [41] & 128 & Not specified & Southern blot analysis & Ratio $>2$ (relative to normal mucosa) & 10.2 \\
\hline Lee et al. [91] & 472 & IB-IV & PCR based & $\mathrm{GCN} \geq 4$ & 21.2 \\
\hline Shi et al. [92] & 128 & $\mathrm{I}-\mathrm{IV}$ & PCR based & $\mathrm{GCN} \geq 4$ & 30.5 \\
\hline
\end{tabular}

CEP7 centromeric portion of chromosome 7, FISH fluorescence in situ hybridization, GCN gene copy number, $P C R$ polymerase chain reaction

Indeed, a phase I trial of crizotinib for patients with $M E T$-amplification-positive NSCLC (NCT00585195) found that of the 12 evaluable patients, four individuals (33\%) showed a partial response, one of whom had an intermediate $M E T / C E P 7$ ratio (greater than 2.2 to less than 5.0) and three had a high MET/CEP7 ratio (5.0 or greater) [94]. Furthermore, crizotinib also induced a partial response in one patient with glioblastoma [95] and opne patient with squamous cell lung cancer [96], with both tumors being found to be positive for $M E T$ amplification (MET/CEP7 ratio greater than 2.2) as determined by FISH. Accumulating clinical evidence thus suggests that $M E T$ amplification as strictly defined by a MET/CEP7 ratio greater than 2.2 has the potential to act as an oncogenic driver and thereby to render at least a subset of affected tumors responsive to crizotinib [87].

Further clinical trials of selective MET TKIs are thus strongly warranted for patients with metastatic gastric cancer positive for $M E T$ amplification as strictly defined by a MET/CEP7 ratio greater than 2.2 determined by FISH.

\section{Conclusion}

Preclinical evidence has suggested that the HGF-MET axis and MET amplification are potential "druggable" targets in gastric cancer, with both HGF- or MET-targeted antibodies and MET TKIs currently being the subject of intensive clinical investigation. Given that antibodies to HGF or MET antagonize HGF binding to MET, they are designed to overcome aberrant signaling by the HGF-MET axis, and MET overexpression as determined by immunohistochemistry has been adopted as a predictive biomarker for treatment with these drugs. However, recent randomized trials of rilotumumab and onartuzumab have shown disappointing results for patients with gastric cancer selected on the basis of MET positivity by immunohistochemistry, suggesting that immunohistochemistry alone is unreliable for selection of the target population. Further study is thus warranted to establish a biomarker that will allow selection of a subpopulation of gastric cancer patients likely to benefit from the antibodies.

On the other hand, most MET TKIs are designed to target the active site in the intracellular domain of the receptor and thereby to inhibit receptor phosphorylation and downstream signaling. Preclinical models have shown MET TKIs to have substantial antitumor activity against gastric cancer positive for MET amplification. However, $M E T$ amplification has not been well defined in patients with gastric cancer, possibly in part because of the difficulty in evaluating gene amplification. A phase I trial of crizotinib suggested that tumors with $M E T$ amplification as strictly defined by a MET/CEP7 ratio greater than 2.2 and determined by FISH are potentially sensitive to MET TKI treatment. Further clinical trials of selective MET TKIs are thus strongly warranted for patients with metastatic gastric cancer positive for $M E T$ amplification as strictly defined by FISH.

\section{Compliance with ethical standards}

Conflict of interest The authors declare that they have no conflict of interest.

Ethical standards This article does not contain any studies with human or animal subjects performed by any of the authors. 


\section{References}

1. Jemal A, Bray F, Center MM, Ferlay J, Ward E, Forman D. Global cancer statistics. CA Cancer J Clin. 2011;61:69-90.

2. Van Cutsem E, Moiseyenko VM, Tjulandin S, Majlis A, Constenla M, Boni C, et al. Phase III study of docetaxel and cisplatin plus fluorouracil compared with cisplatin and fluorouracil as firstline therapy for advanced gastric cancer: a report of the V325 Study Group. J Clin Oncol. 2006;24:4991-7.

3. Cunningham D, Starling N, Rao S, Iveson T, Nicolson M, Coxon $\mathrm{F}$, et al. Capecitabine and oxaliplatin for advanced esophagogastric cancer. N Engl J Med. 2008;358:36-46.

4. Koizumi W, Narahara H, Hara T, Takagane A, Akiya T, Takagi $\mathrm{M}$, et al. S-1 plus cisplatin versus S-1 alone for first-line treatment of advanced gastric cancer (SPIRITS trial): a phase III trial. Lancet Oncol. 2008;9:215-21.

5. Kang YK, Kang WK, Shin DB, Chen J, Xiong J, Wang J, et al. Capecitabine/cisplatin versus 5 -fluorouracil/cisplatin as first-line therapy in patients with advanced gastric cancer: a randomised phase III noninferiority trial. Ann Oncol. 2009;20:666-73.

6. Ajani JA, Rodriguez W, Bodoky G, Moiseyenko V, Lichinitser M, Gorbunova V, et al. Multicenter phase III comparison of cisplatin/S-1 with cisplatin/infusional fluorouracil in advanced gastric or gastroesophageal adenocarcinoma study: the FLAGS trial. J Clin Oncol. 2010;28:1547-53.

7. Bang YJ, Van Cutsem E, Feyereislova A, Chung HC, Shen L, Sawaki A, et al. Trastuzumab in combination with chemotherapy versus chemotherapy alone for treatment of HER2-positive advanced gastric or gastro-oesophageal junction cancer (ToGA): a phase 3, open-label, randomised controlled trial. Lancet. 2010;376:687-97.

8. Ohtsu A, Shah MA, Van Cutsem E, Rha SY, Sawaki A, Park SR, et al. Bevacizumab in combination with chemotherapy as firstline therapy in advanced gastric cancer: a randomized, doubleblind, placebo-controlled phase III study. J Clin Oncol. 2011;29:3968-76.

9. Mok TS, Wu YL, Thongprasert S, Yang CH, Chu DT, Saijo N, et al. Gefitinib or carboplatin-paclitaxel in pulmonary adenocarcinoma. N Engl J Med. 2009;361:947-57.

10. Maemondo M, Inoue A, Kobayashi K, Sugawara S, Oizumi S, Isobe $\mathrm{H}$, et al. Gefitinib or chemotherapy for non-small-cell lung cancer with mutated EGFR. N Engl J Med. 2010;362:2380-8.

11. Shaw AT, Kim DW, Nakagawa K, Seto T, Crino L, Ahn MJ, et al. Crizotinib versus chemotherapy in advanced ALK-positive lung cancer. N Engl J Med. 2013;368:2385-94.

12. Slamon DJ, Leyland-Jones B, Shak S, Fuchs H, Paton V, Bajamonde A, et al. Use of chemotherapy plus a monoclonal antibody against HER2 for metastatic breast cancer that overexpresses HER2. N Engl J Med. 2001;344:783-92.

13. Hofmann M, Stoss O, Shi D, Buttner R, van de Vijver M, Kim W, et al. Assessment of a HER2 scoring system for gastric cancer: results from a validation study. Histopathology. 2008;52:797-805.

14. Tanner M, Hollmen M, Junttila TT, Kapanen AI, Tommola S, Soini Y, et al. Amplification of HER-2 in gastric carcinoma: association with topoisomerase II $\alpha$ gene amplification, intestinal type, poor prognosis and sensitivity to trastuzumab. Ann Oncol. 2005;16:273-8.

15. Gravalos C, Jimeno A. HER2 in gastric cancer: a new prognostic factor and a novel therapeutic target. Ann Oncol. 2008;19:1523-9.

16. Waddell T, Verheij M, Allum W, Cunningham D, Cervantes A, Arnold D. Gastric cancer: ESMO-ESSO-ESTRO clinical practice guidelines for diagnosis, treatment and follow-up. Ann Oncol. 2013;24(Suppl 6):vi57-63.
17. Okines A, Verheij M, Allum W, Cunningham D, Cervantes A. Gastric cancer: ESMO clinical practice guidelines for diagnosis, treatment and follow-up. Ann Oncol. 2010;21(Suppl 5):v50-4.

18. Ajani JA, Barthel JS, Bekaii-Saab T, Bentrem DJ, D'Amico TA, Das P, et al. Gastric cancer. J Natl Compr Canc Netw. 2010;8:378-409.

19. Deng N, Goh LK, Wang H, Das K, Tao J, Tan IB, et al. A comprehensive survey of genomic alterations in gastric cancer reveals systematic patterns of molecular exclusivity and co-occurrence among distinct therapeutic targets. Gut. 2012;61:673-84.

20. The Cancer Genome Atlas Research Network. Comprehensive molecular characterization of gastric adenocarcinoma. Nature. 2014;513:202-9.

21. Gherardi E, Birchmeier W, Birchmeier C, Vande Woude G. Targeting MET in cancer: rationale and progress. Nat Rev Cancer. 2012;12:89-103.

22. Corso S, Comoglio PM, Giordano S. Cancer therapy: can the challenge be MET? Trends Mol Med. 2005;11:284-92.

23. Christensen JG, Burrows J, Salgia R. c-MET as a target for human cancer and characterization of inhibitors for therapeutic intervention. Cancer Lett. 2005;225:1-26.

24. Davis IJ, McFadden AW, Zhang Y, Coxon A, Burgess TL, Wagner AJ, et al. Identification of the receptor tyrosine kinase c-MET and its ligand, hepatocyte growth factor, as therapeutic targets in clear cell sarcoma. Cancer Res. 2010;70:639-45.

25. Di Renzo MF, Olivero M, Martone T, Maffe A, Maggiora P, Stefani AD, et al. Somatic mutations of the MET oncogene are selected during metastatic spread of human HNSC carcinomas. Oncogene. 2000;19:1547-55.

26. Park WS, Dong SM, Kim SY, Na EY, Shin MS, Pi JH, et al. Somatic mutations in the kinase domain of the Met/hepatocyte growth factor receptor gene in childhood hepatocellular carcinomas. Cancer Res. 1999;59:307-10.

27. Schmidt L, Duh FM, Chen F, Kishida T, Glenn G, Choyke P, et al. Germline and somatic mutations in the tyrosine kinase domain of the MET proto-oncogene in papillary renal carcinomas. Nat Genet. 1997;16:68-73.

28. Birchmeier C, Birchmeier W, Gherardi E, Vande Woude GF. Met, metastasis, motility and more. Nat Rev Mol Cell Biol. 2003;4:915-25.

29. Tanizaki J, Okamoto I, Sakai K, Nakagawa K. Differential roles of trans-phosphorylated EGFR, HER2, HER3, and RET as heterodimerisation partners of MET in lung cancer with MET amplification. Br J Cancer. 2011;105:807-13.

30. Engelman JA, Zejnullahu K, Mitsudomi T, Song Y, Hyland C, Park JO, et al. MET amplification leads to gefitinib resistance in lung cancer by activating ERBB3 signaling. Science. 2007;316:1039-43.

31. Yano S, Wang W, Li Q, Matsumoto K, Sakurama H, Nakamura $\mathrm{T}$, et al. Hepatocyte growth factor induces gefitinib resistance of lung adenocarcinoma with epidermal growth factor receptor-activating mutations. Cancer Res. 2008;68:9479-87.

32. Troiani T, Martinelli E, Napolitano S, Vitagliano D, Ciuffreda LP, Costantino $S$, et al. Increased TGF- $\alpha$ as a mechanism of acquired resistance to the anti-EGFR inhibitor cetuximab through EGFR-MET interaction and activation of MET signaling in colon cancer cells. Clin Cancer Res. 2013;19:6751-65.

33. Bardelli A, Corso S, Bertotti A, Hobor S, Valtorta E, Siravegna $\mathrm{G}$, et al. Amplification of the MET receptor drives resistance to anti-EGFR therapies in colorectal cancer. Cancer Discov. 2013;3:658-73.

34. Chen CT, Kim H, Liska D, Gao S, Christensen JG, Weiser MR. MET activation mediates resistance to lapatinib inhibition of HER2-amplified gastric cancer cells. Mol Cancer Ther. 2012;11:660-9. 
35. Lee YY, Kim HP, Kang MJ, Cho BK, Han SW, Kim TY, et al. Phosphoproteomic analysis identifies activated MET-axis PI3K/ AKT and MAPK/ERK in lapatinib-resistant cancer cell line. Exp Mol Med. 2013;45:e64.

36. Zhang Z, Wang J, Ji D, Wang C, Liu R, Wu Z, et al. Functional genetic approach identifies MET, HER3, IGF1R, INSR pathways as determinants of lapatinib unresponsiveness in HER2-positive gastric cancer. Clin Cancer Res. 2014;20:4559-73.

37. Danilkovitch-Miagkova A, Zbar B. Dysregulation of Met receptor tyrosine kinase activity in invasive tumors. J Clin Invest. 2002;109:863-7.

38. Park WS, Oh RR, Kim YS, Park JY, Shin MS, Lee HK, et al. Absence of mutations in the kinase domain of the Met gene and frequent expression of Met and HGF/SF protein in primary gastric carcinomas. APMIS. 2000;108:195-200.

39. Lee JH, Han SU, Cho H, Jennings B, Gerrard B, Dean M, et al. A novel germ line juxtamembrane Met mutation in human gastric cancer. Oncogene. 2000;19:4947-53.

40. Chen JD, Kearns S, Porter T, Richards FM, Maher ER, Teh BT. MET mutation and familial gastric cancer. J Med Genet. 2001;38:E26.

41. Nakajima M, Sawada H, Yamada Y, Watanabe A, Tatsumi M, Yamashita $\mathrm{J}$, et al. The prognostic significance of amplification and overexpression of c-MET and c-ERB B-2 in human gastric carcinomas. Cancer. 1999;85:1894-902.

42. Hara T, Ooi A, Kobayashi M, Mai M, Yanagihara K, Nakanishi I. Amplification of c-myc, K-sam, and c-MET in gastric cancers: detection by fluorescence in situ hybridization. Lab Invest. 1998;78:1143-53.

43. Tsugawa K, Yonemura Y, Hirono Y, Fushida S, Kaji M, Miwa K, et al. Amplification of the c-MET, c-ERBB-2 and epidermal growth factor receptor gene in human gastric cancers: correlation to clinical features. Oncology. 1998;55:475-81.

44. Toiyama Y, Yasuda H, Saigusa S, Matushita K, Fujikawa H, Tanaka K, et al. Co-expression of hepatocyte growth factor and c-MET predicts peritoneal dissemination established by autocrine hepatocyte growth factor/c-MET signaling in gastric cancer. Int $\mathbf{J}$ Cancer. 2012;130:2912-21.

45. Wu X, Chen X, Zhou Q, Li P, Yu B, Li J, et al. Hepatocyte growth factor activates tumor stromal fibroblasts to promote tumorigenesis in gastric cancer. Cancer Lett. 2013;335:128-35.

46. Zou HY, Li Q, Lee JH, Arango ME, Burgess K, Qiu M, et al. Sensitivity of selected human tumor models to PF-04217903, a novel selective c-MET kinase inhibitor. Mol Cancer Ther. 2012;11:1036-47.

47. Smolen GA, Sordella R, Muir B, Mohapatra G, Barmettler A, Archibald H, et al. Amplification of MET may identify a subset of cancers with extreme sensitivity to the selective tyrosine kinase inhibitor PHA-665752. Proc Natl Acad Sci U S A. 2006;103:2316-21.

48. Okamoto W, Okamoto I, Arao T, Kuwata K, Hatashita E, Yamaguchi $\mathrm{H}$, et al. Antitumor action of the MET tyrosine kinase inhibitor crizotinib (PF-02341066) in gastric cancer positive for MET amplification. Mol Cancer Ther. 2012;11:1557-64.

49. Kawakami H, Okamoto I, Arao T, Okamoto W, Matsumoto K, Taniguchi H, et al. MET amplification as a potential therapeutic target in gastric cancer. Oncotarget. 2013;4:9-17.

50. Burgess TL, Sun J, Meyer S, Tsuruda TS, Sun J, Elliott G, et al. Biochemical characterization of AMG 102: a neutralizing, fully human monoclonal antibody to human and nonhuman primate hepatocyte growth factor. Mol Cancer Ther. 2010;9:400-9.

51. Iveson T, Donehower RC, Davidenko I, Tjulandin S, Deptala A, Harrison $\mathrm{M}$, et al. Rilotumumab in combination with epirubicin, cisplatin, and capecitabine as first-line treatment for gastric or oesophagogastric junction adenocarcinoma: an open-label, dose de-escalation phase $1 \mathrm{~b}$ study and a double-blind, randomised phase 2 study. Lancet Oncol. 2014;15:1007-18.

52. Zhu M, Tang R, Doshi S, Oliner KS, Dubey S, Jiang Y, et al. Exposure-response analysis of rilotumumab in gastric cancer: the role of tumour MET expression. Br J Cancer. 2015;112:429-37.

53. Cunningham D, Al-Batran S, Davidenko I, Ilson DH, Murad A, Tebbutt N, et al. RILOMET-1: an international phase III multicenter, randomized, double-blind, placebo-controlled trial of rilotumumab plus epirubicin, cisplatin, and capecitabine (ECX) as first-line therapy in patients with advanced MET-positive gastric or gastroesophageal junction (G/GEJ) adenocarcinoma. J Clin Oncol. 2013;31(15 Suppl):TPS4153.

54. Cunningham D, Tebbutt N, Davidenko I, Murad A, Al-Batran S, Ilson DH, et al. Phase III, randomized, double-blind, multicenter, placebo $(\mathrm{P})$-controlled trial of rilotumumab $(\mathrm{R})$ plus epirubicin, cisplatin and capecitabine (ECX) as first-line therapy in patients (pts) with advanced MET-positive (pos) gastric or gastroesophageal junction (G/GEJ) cancer: RILOMET-1 study. J Clin Oncol 2015;33(15 Suppl):4000.

55. Jin H, Yang R, Zheng Z, Romero M, Ross J, Bou-Reslan H, et al. MetMAb, the one-armed 5D5 anti-c-MET antibody, inhibits orthotopic pancreatic tumor growth and improves survival. Cancer Res. 2008;68:4360-8.

56. Merchant M, Ma X, Maun HR, Zheng Z, Peng J, Romero M, et al. Monovalent antibody design and mechanism of action of onartuzumab, a MET antagonist with anti-tumor activity as a therapeutic agent. Proc Natl Acad Sci U S A. 2013;110:E2987-96.

57. Catenacci DV, Henderson L, Xiao SY, Patel P, Yauch RL, Hegde $\mathrm{P}$, et al. Durable complete response of metastatic gastric cancer with anti-Met therapy followed by resistance at recurrence. Cancer Discov. 2011;1:573-9.

58. Spigel DR, Ervin TJ, Ramlau RA, Daniel DB, Goldschmidt JH Jr, Blumenschein GR Jr, et al. Randomized phase II trial of onartuzumab in combination with erlotinib in patients with advanced non-small-cell lung cancer. J Clin Oncol. 2013;31:4105-14.

59. Spigel DR, Edelman MJ, Mok T, O’Byrne K, Paz-Ares L, Yu W, et al. Treatment rationale study design for the MetLung trial: a randomized, double-blind phase III study of onartuzumab (Met$\mathrm{MAb}$ ) in combination with erlotinib versus erlotinib alone in patients who have received standard chemotherapy for stage IIIB or IV met-positive non-small-cell lung cancer. Clin Lung Cancer. 2012;13:500-4.

60. Spigel DR, Edelman MJ, O'Byrne K, Paz-Ares L, Shames DS, $\mathrm{Yu} \mathrm{Y}$, et al. Onartuzumab plus erlotinib versus erlotinib in previously treated stage IIIb or IV NSCLC: results from the pivotal phase III randomized, multicenter, placebo-controlled METLung (OAM4971g) global trial. J Clin Oncol. 2014;32(15 Suppl):8000.

61. Shah MA, Cho JY, Huat ITB, Tebbutt N, Yen CJ, Kang A, et al. Randomized phase II study of FOLFOX +/- MET inhibitor, onartuzumab $(\mathrm{O})$, in advanced gastroesophageal adenocarcinoma (GEC). J Clin Oncol. 2015;33(3 Suppl):2.

62. Cunningham D, Bang YJ, Tabernero J, Shah MA, Lordick F, Hack SP. MetGastric: a randomized phase III study of onartuzumab (MetMAb) in combination with mFOLFOX6 in patients with metastatic HER2-negative and MET-positive adenocarcinoma of the stomach or gastroesophageal junction. J Clin Oncol. 2013;31(15 Suppl):TPS4155.

63. Shah MA, Bang YJ, Lordick F, Tabernero J, Chen M, Hack SP, et al. METGastric: a phase III study of onartuzumab plus mFOLFOX6 in patients with metastatic HER2-negative (HER2-) and MET-positive (MET+) adenocarcinoma of the stomach or gastroesophageal junction (GEC). J Clin Oncol. 2015;33(15 Suppl):4012.

64. Lee HE, Kim MA, Lee HS, Jung EJ, Yang HK, Lee BL, et al. MET in gastric carcinomas: comparison between protein 
expression and gene copy number and impact on clinical outcome. Br J Cancer. 2012;107(2):325-33.

65. Ma J, Ma J, Meng Q, Zhao ZS, Xu WJ. Prognostic value and clinical pathology of MACC-1 and c-MET expression in gastric carcinoma. Pathol Oncol Res. 2013;19:821-32.

66. Ha SY, Lee J, Kang SY, Do IG, Ahn S, Park JO, et al. MET overexpression assessed by new interpretation method predicts gene amplification and poor survival in advanced gastric carcinomas. Mod Pathol. 2013;26:1632-41.

67. Liu YJ, Shen D, Yin X, Gavine P, Zhang T, Su X, et al. HER2, MET and FGFR2 oncogenic driver alterations define distinct molecular segments for targeted therapies in gastric carcinoma. Br J Cancer. 2014;110:1169-78.

68. Nagatsuma AK, Aizawa M, Kuwata T, Doi T, Ohtsu A, Fujii H, Ochiai A. Expression profiles of HER2, EGFR, MET and FGFR2 in a large cohort of patients with gastric adenocarcinoma. Gastric Cancer. 2014;18(2):227-38.

69. Fuse N, Kuboki Y, Kuwata T, Nishina T, Kadowaki S, Shinozaki E, et al. Prognostic impact of HER2, EGFR, and c-MET status on overall survival of advanced gastric cancer patients. Gastric Cancer. 2015. doi:10.1007/s10120-015-0471-6.

70. Koeppen H, Rost S, Yauch RL. Developing biomarkers to predict benefit from HGF/MET pathway inhibitors. J Pathol. 2014;232:210-8.

71. Smith NR, Womack C. A matrix approach to guide IHC-based tissue biomarker development in oncology drug discovery. J Pathol. 2014;232:190-8.

72. Bhowmick NA, Neilson EG, Moses HL. Stromal fibroblasts in cancer initiation and progression. Nature. 2004;432:332-7.

73. Boccaccio C, Ando M, Tamagnone L, Bardelli A, Michieli P, Battistini $\mathrm{C}$, et al. Induction of epithelial tubules by growth factor HGF depends on the STAT pathway. Nature. 1998;391:285-8.

74. Abounader R, Reznik T, Colantuoni C, Martinez-Murillo F, Rosen EM, Laterra J. Regulation of c-MET-dependent gene expression by PTEN. Oncogene. 2004;23:9173-82.

75. Ivan M, Bond JA, Prat M, Comoglio PM, Wynford-Thomas D. Activated ras and ret oncogenes induce over-expression of c-MET (hepatocyte growth factor receptor) in human thyroid epithelial cells. Oncogene. 1997;14:2417-23.

76. Pennacchietti S, Michieli P, Galluzzo M, Mazzone M, Giordano $\mathrm{S}$, Comoglio PM. Hypoxia promotes invasive growth by transcriptional activation of the met protooncogene. Cancer Cell. 2003;3:347-61.

77. Zhang YW, Su Y, Volpert OV, Vande Woude GF. Hepatocyte growth factor/scatter factor mediates angiogenesis through positive VEGF and negative thrombospondin 1 regulation. Proc Natl Acad Sci U S A. 2003;100:12718-23.

78. Finisguerra V, Di Conza G, Di Matteo M, Serneels J, Costa S, Thompson AA, et al. MET is required for the recruitment of antitumoural neutrophils. Nature. 2015;522:349-53.

79. Shah MA, Wainberg ZA, Catenacci DV, Hochster HS, Ford J, Kunz P, et al. Phase II study evaluating 2 dosing schedules of oral foretinib (GSK1363089), cMET/VEGFR2 inhibitor, in patients with metastatic gastric cancer. PLoS ONE. 2013;8:e54014.

80. Katayama R, Aoyama A, Yamori T, Qi J, Oh-hara T, Song Y, et al. Cytotoxic activity of tivantinib (ARQ 197) is not due solely to c-MET inhibition. Cancer Res. 2013;73:3087-96.

81. Kang YK, Muro K, Ryu MH, Yasui H, Nishina T, Ryoo BY, et al. A phase II trial of a selective c-MET inhibitor tivantinib (ARQ 197) monotherapy as a second- or third-line therapy in the patients with metastatic gastric cancer. Invest New Drugs. 2014;32:355-61.

82. Tanizaki J, Okamoto I, Okamoto K, Takezawa K, Kuwata K, Yamaguchi $\mathrm{H}$, et al. MET tyrosine kinase inhibitor crizotinib (PF-
02341066) shows differential antitumor effects in non-small cell lung cancer according to MET alterations. J Thorac Oncol. 2011;6:1624-31.

83. Kwak EL, Bang YJ, Camidge DR, Shaw AT, Solomon B, Maki $\mathrm{RG}$, et al. Anaplastic lymphoma kinase inhibition in non-smallcell lung cancer. N Engl J Med. 2010;363:1693-703.

84. Lennerz JK, Kwak EL, Ackerman A, Michael M, Fox SB, Bergethon $\mathrm{K}$, et al. MET amplification identifies a small and aggressive subgroup of esophagogastric adenocarcinoma with evidence of responsiveness to crizotinib. J Clin Oncol. 2011;29:4803-10.

85. Yang Y, Wu N, Shen J, Teixido C, Sun X, Lin Z, et al. MET overexpression and amplification define a distinct molecular subgroup for targeted therapies in gastric cancer. Gastric Cancer. 2015. doi:10.1007/s10120-015-0545-5.

86. Kwak EL, Lorusso P, Hamid O, Janku F, Kittaneh M, Virgil D, Catenacci T, Chan E, Bekaii-Saab TS, Amore B, Hwang YC, Tang R, Ngarmchamnanrith G, Hong DS. Clinical activity of AMG 337, an oral MET kinase inhibitor, in adult patients (pts) with MET-amplified gastroesophageal junction (GEJ), gastric (G), or esophageal (E) cancer. J Clin Oncol. 2015;33(3 Suppl):1.

87. Kawakami H, Okamoto I, Okamoto W, Tanizaki J, Nakagawa K, Nishio K. Targeting MET amplification as a new oncogenic driver. Cancers (Basel). 2014;6:1540-52.

88. Janjigian YY, Tang LH, Coit DG, Kelsen DP, Francone TD, Weiser MR, et al. MET expression and amplification in patients with localized gastric cancer. Cancer Epidemiol Biomark Prev. 2011;20:1021-7.

89. An X, Wang F, Shao Q, Wang F-H, Wang Z-Q, Chen C, et al. METamplification is not rare and predicts unfavorable clinical outcomes in patients with recurrent/metastatic gastric cancer after chemotherapy. Cancer. 2014;120:675-82.

90. Graziano F, Galluccio N, Lorenzini P, Ruzzo A, Canestrari E, D'Emidio S, et al. Genetic activation of the MET pathway and prognosis of patients with high-risk, radically resected gastric cancer. J Clin Oncol. 2011;29:4789-95.

91. Lee J, Seo JW, Jun HJ, Ki CS, Park SH, Park YS, et al. Impact of MET amplification on gastric cancer: possible roles as a novel prognostic marker and a potential therapeutic target. Oncol Rep. 2011;25:1517-24.

92. Shi J, Yao D, Liu W, Wang N, Lv H, He N, et al. Frequent gene amplification predicts poor prognosis in gastric cancer. Int $\mathrm{J}$ Mol Sci. 2012;13:4714-26.

93. Vanden Bempt I, Van Loo P, Drijkoningen M, Neven P, Smeets A, Christiaens MR, et al. Polysomy 17 in breast cancer: clinicopathologic significance and impact on HER-2 testing. J Clin Oncol. 2008;26:4869-74.

94. Camidge DR, Ou S-HI, Shapiro G, Otterson GA, Villaruz LC, Villalona-Calero MA, et al. Efficacy and safety of crizotinib in patients with advanced c-MET-amplified non-small cell lung cancer (NSCLC). J Clin Oncol. 2014;32:(15 Suppl):8001.

95. Chi AS, Batchelor TT, Kwak EL, Clark JW, Wang DL, Wilner $\mathrm{KD}$, et al. Rapid radiographic and clinical improvement after treatment of a MET-amplified recurrent glioblastoma with a mesenchymal-epithelial transition inhibitor. J Clin Oncol. 2012;30:e30-3.

96. Schwab R, Petak I, Kollar M, Pinter F, Varkondi E, Kohanka A, et al. Major partial response to crizotinib, a dual MET/ALK inhibitor, in a squamous cell lung (SCC) carcinoma patient with de novo c-MET amplification in the absence of ALK rearrangement. Lung Cancer. 2014;83:109-11. 